\title{
ANALISE DA VARIAÇÃO DA INTENSIDADE ESPECTRAL DE PROTEÍNA E ÁGUA NA DERME APÓS EXPOSIÇÃO À RADIAÇÃO DE INFRAVERMELHO
}

\author{
Aline Priscila Campos Pereira ${ }^{1}$ \\ Michely Glenda Pereira da Silva ${ }^{2}$ \\ Fernanda R. Moraes ${ }^{3}$ \\ Taciana D. Magrini Alva ${ }^{4}$ \\ Airton A. Martin ${ }^{5}$
}

Resumo: A irradiação da luz infravermelha (IR) diminui o conteúdo de carotenoides, $\beta$-caroteno e licopeno, favorece a formação de espécies reativas de oxigênio (ROS) e metalo proteinases de matriz (MMP) influenciando na formação dos radicais livres, diminuição de proteínas e conteúdo hídrico na pele. O objetivo desse estudo foi analisar a variação da intensidade espectral de proteína e água na derme após exposição à irradiação (IR) por meio de doses de 50 e $150 \mathrm{~mW}$. Foram realizadas medidas por meio da técnica de espectroscopia Raman Confocal na região do antebraço. Observou-se em geral diminuição na intensidade do pico de proteína para as duas doses de irradiação, quanto à água não houve diminuição para um participante. Conclui-se que a técnica usada é uma ferramenta imortante para análise das alterações dos arranjos quimicos presentes na pele após irradiação da luz (IR).

Palavras-chave: Água corporal; Análise espectral raman; Derme; Pele; Radiação.

\footnotetext{
1 Graduação em Ciências Biológicas pela Universidade do Vale do Paraíba, Brasil. E-mail: allinneferrara@gmail.com.

2 Doutoranda em Engenharia Biomédica - Instituto de Pesquisa e Desenvolvimento - IP\&D/Universidade do Vale do Paraíba - UNIVAP, Brasil. E-mail: michely.glenda@hotmail.com.

3 Graduação em Engenharia Química pela Universidade do Vale do Paraíba, Brasil. E-mail: fereismoraes17@gmail.com.

4 Doutorado em Nanociências e Materiais Avançados pela Universidade Federal do ABC, Brasil(2015), Pós Doutorado da Universidade do Vale do Paraíba, Brasil. E-mail: texying@gmail.com.

${ }^{5}$ Coordenador do Laboratório de Espectroscopia Vibracional Biomédica e Lab. PROBES- Desenvolvimentos de Projetos em Biomedicina e Engenharias, Brasil. E-mail: amartin@univap.com.br.
} 